\title{
O Conceito de País em Uma Viagem à Índia
}

\author{
João Albuquerque \\ University of California Santa Barbara
}

Resumo: Pretende o presente estudo expor o questionamento que sofrem alguns critérios universalmente aceites como formadores da noção de país na obra Uma Viagem à Índia, de Gonçalo M. Tavares. Uma vez que nesta obra não é predeterminada à ideia de país qualquer contexto de ordem pragmática, ficam em certo sentido anulados os critérios externos habitualmente utilizados para balizá-la. Sendo a anulação de tais critérios afirmada de modo explícito na obra, traçarei um breve mapa destas negações. Redundando a explicitação destas negações numa noção de país que sai da própria possibilidade de sobredeterminação por via de qualquer meta-linguagem, de qualquer fundamento místico, implica isto um devir intrínseco a tal noção, uma força metamórfica que não lhe permita fixar-se sob nenhuma forma estanque. Um conceito, por conseguinte, em permanente restruturação, cuja força não é bruta nem modeladora, mas delicada e maleável que assenta numa intensidade inteligente e complexa. Para findar, articular-se-á esta noção mutável de país com as noções de tempo e de espaço.

Palavras-chave: Uma Viagem à Índia; Gonçalo M. Tavares; país

Abstract: This paper means to expose the way some universally accepted criteria which form the notion of country in the work Uma Viagem à Índia, by Gonçalo M. Tavares, are questioned. Since no context of pragmatic order is predetermined to the idea of country in this work, in a sense the external criteria usually employed to mark it out are cancelled. Since the annulment of such criteria is explicitly stated in the work, I will briefly map out these denials. The explanation of these denials resulting in a notion of country which is outside the very possibility of overdetermination by way of any meta-language, of any mystical fundament, one can argue 
that this implies a becoming that is intrinsic to such a notion, a metamorphic force which does not allow it to settle itself under any stagnant form. A concept, therefore, in constant restructuration, whose force is neither brute nor modelling but delicate and malleable - which rests upon an intelligent and complex intensity. Finally, this mutable notion of country will be articulated with the notions of time and space.

Keywords: Uma Viagem à Índia; Gonçalo M. Tavares; country

\section{Introdução}

\subsection{Uma Viagem à Índia: paródia d' Os Lusíadas}

Lançando um olhar comparativo para ambos os primeiros cantos de Os Lusíadas e de Uma Viagem à Índia, logo se percebe que existe um diálogo intertextual que este poema estabelece com aquele. As 41 estrofes de abertura do texto camoniano, que contêm o código épico renascentista composto pela Proposição (Lus, I, 1-3), ${ }^{1}$ Invocação (Lus, I, 4-5) e Dedicatória (Lus, I, 6-18), mais o episódio do Consílio dos Deuses no Olímpo (Lus, I, 19-41) que precede o início da odisseia marítima de Vasco da Gama, encontram correspondência no texto gonçalino, apresentando-se aqui como um preâmbulo digressivo da narração da viagem do seu personagem principal, Bloom.

Uma leitura aparelhada destas estrofes começa por revelar o referido preâmbulo gonçalino como um texto camoniano às avessas. Enquanto Camões enuncia logo de entrada o objecto do seu canto - os altos feitos e o valor superlativo do povo lusitano -, o narrador de Uma Viagem à Índia põe ao invés a ênfase naquilo que o leitor não poderá esperar da obra (usando, para isso, abundantemente, a anáfora "Não falaremos..." nas nove primeiras estrofes, com eco posterior e em forma de corolário na $44^{a}$ estrofe), a saber, que o conteúdo da sua narrativa configure uma epopeia no enunciado sentido camoniano do termo: "Não falaremos então de um povo / que é demasiado e muito. / Falaremos nesta epopeia apenas de um homem: Bloom." (UVI, I, 44:1-3) E se é afirmada por contraponto a existência na narrativa de um único herói (Bloom é assim apodado ao longo da narrativa ironicamente?), tal não é feito através da exaltação nele de quaisquer qualidades ou acções moralmente superiores, mitificáveis ou sequer grandiosas, mas tão-somente humanas: 
E digamos que: acima do nível dos olhos age

quem espera que os elementos divinos,

o acaso e o destino, resolvam o que a psicologia

e os utensílios não conseguem perceber.

Ao nível dos olhos, pelo contrário, age quem acredita

que os gestos humanos são ainda, ou são agora,

a mais forte aceleração

que se pode introduzir no mundo.

Quem age abaixo do nível dos olhos reconhece

que o avanço não foi suficiente

e que só a parte animal do homem,

ou a parte que se humilha, podem solucionar os conflitos.

Saltar, argumentar, rastejar

- eis, em síntese, três formas humanas

de responder a um único mundo.

(E Bloom vai praticar todas.) (UVI, I, 37-8: 4-8;1-12)

Confrontando esta citação com as acções que os nautas camonianos praticam ao longo de todo o relato, vemos que afinal a distância que separa o herói gonçalino destes não é assim tão grande, que, além da entrega a um destino em certos momentos totalmente incontrolável (sendo aí os deuses quem assume as suas rédeas), também o uso do poder de argumentação (em diversas paragens ao longo do itinerário, inclusive na chegada à Índia) e até mesmo o acobardamento e a fuga (na sequência do difícil relacionamento e comércio com os indianos) constituem um leque diversificado de modos de lidar com o mundo por parte daqueles.

Direcciona isto a atenção para uma característica fulcral do texto de Camões: o profundo contraste que existe entre uma retórica nacionalista geral, codificada epicamente no sentido de os personagens revelarem elevado mérito moral e/ou guerreiro nas acções que praticam, e uma narração realista da acção, na qual os mesmos personagens são descritos como homens capazes do melhor e do pior, tanto quanto do trivial. Afigurando-se este um contraste vincado no texto camoniano, não é todavia o único. Diversos críticos de 
nomeada, como, por exemplo, António José Saraiva, Fernando Gil, Hélder Macedo, Jorge de Sena e Eduardo Lourenço, formam as suas concepções sobre a poesia camoniana - tanto a épica como a lírica - com base nas contradições que a urdem.

Leio então a apresentação de Bloom como um herói contraditório (UVI, I, 44: 4-5) simultaneamente como uma transcontextualização irónica directa da auto -referencialidade heróica camoniana e uma transcontextualização irónica metaliterária do cariz contraditório da poesia de Camões.

Transcontextualização irónica da auto-referencialidade heróica camoniana enquanto superioridade moral, estética ou guerreira. Bloom, ao invés, é já inteiramente um personagem romanesco, um homem sem qualidades pós-joyciano (e aqui fica assinalada de passagem outra evidente transcontextualização irónica ${ }^{2}$ ) que resolve partir de Lisboa inopinadamente, depois de uma peripécia passional descrita retrospectivamente como o homicídio da sua amada Mary pelo seu pai (UVI, III, 122-4) e deste, num acto de vingança, por si próprio. Numa palavra, um (não-?)herói jamais associável a uma cultura dominante, não constituindo os seus actos qualquer repres entatividade popular, exemplaridade moral, força inelutável da natureza ou avatar divino.

Transcontextualização irónica metaliterária do cariz contraditório da poesia de Camões sobretudo porque, dos dois ideais contraditórios perseguidos por Bloom, a sabedoria e o esquecimento (UVI, I, 10: 4-6), o segundo é precisamente um contra-ideal para Camões (1981: 127-8), algo contra o qual, conscientemente, a sua poesia trabalha:

0 rudo canto meu, que ressuscita

As honras sepultadas

As palmas já passadas

Dos belicosos nossos lusitanos,

Pera tesouro dos futuros anos

Convosco se defende

Da lei leteia à qual tudo se rende.

Atente-se ao comentário que Eduardo Lourenço (2002: 47) produz acerca destes 
versos:

Texto precioso, pois nos confirma na ideia de que a Epopeia nasceu sob o signo da reminiscência, epopeia no passado mais que no presente. Mas texto mais precioso ainda porque nos revela sem ambages a função vital do canto camoniano: esse canto é a única defesa contra a noite da memória, o único gesto mágico que suscita a luz capaz de vencer essas trevas em que se perdem para sempre os ecos dos actos e dos pensamentos dos homens.

A origem de uma valorização diversa da memória e do esquecimento respectivamente em Camões e Bloom advém de uma também diversa relação com o passado: o poema citado mostra que o primeiro pretende-o celebrado, (re)vivido, ressuscitado, enquanto o segundo quer apagá-lo da sua vida, mostra-se-lhe hostil: "Falaremos da hostilidade que Bloom, / o nosso herói, / revelou em relação ao passado" (UVI, I, 10: 1-3).

Em suma, a demanda de Bloom revela-se disjuntiva, não em relação ao poema de Camões na sua totalidade, mas tão-somente em relação ao que este comporta de convenções obsoletas: actos heróicos (UVI, I, 11: 1-4); Verdades (UVI, I, 11: 5-10); grandes abstracções metafísicas (UVI, I, 29-30: 5-9;1-6); mitologias (UVI, I, 3: 1-3); e um passado histórico grandioso sustentado por narrativas mitificadas que exaltam o frenesi cúpido e dominador do homem (UVI, I, 18), pois "Não se trata aqui de encontrar a imortalidade / mas de dar um certo valor ao que é mortal" (UVI, I, 3: 4-5).

Não é, porém, apenas com estas configurações herdadas dos pesos passados que a disjunção se dá, mas também com as suas configurações presentes. A par da ruptura com as grandes abstracções (generalizações) que nada tendem a explicitar ou concretizar, mas tão só a servir de instrumento de imobilização do homem (UVI, I, 29-30: 5-9;1-6), vem a disjunção com as particularidades demasiadamente humanas, onde o uso da língua se mostra domesticado para atingir fins meramente económicos (UVI, I, 32: 1-5), os quais não passam de uma forma alternativa (mais limpa, mais simplificada) do mesmo organismo metafísico cúpido e dominador que se rebate sobre os homens: "Não há dinheiro que suje as 
mãos, / há apenas mãos capazes de sujar esta nova Bíblia, / de página única e bem mais fácil de ler: a nota valiosa" (UVI, II, 22: 1-3). Neste sentido, é-nos dito:

(...) que as discussões universais dos homens

são sempre discussões particulares. (...)

(..)

Cada país é um pormenor que cada habitante utiliza

como melhor lhe convém e como a lei

permite. (UVI, I, 33: 3-4, 9-11)

Serve este raciocínio para mostrar de forma sumária que, concomitantemente à transcontextualização de Os Lusíadas, existe na demanda de Bloom uma sátira sociopolítica do mundo coevo.

\subsection{Problematização e objectivos}

O propósito do subcapítulo anterior foi dar uma breve ideia da natureza (parodística) da relação intertextual que Uma Viagem à Índia estabelece com Os Lusíadas, tendo sido introduzidas nessa tarefa algumas linhas de pensamento imanentes ao texto gonçalino que de certa maneira formam parte de uma ossatura a partir da qual um conceito de país pode ser reconstruído. Pois na demonstração desta relação ficou bem evidente que existe uma tensão interessante entre os dois textos: ruptura e crítica, mas também continuidade e homenagem. Deste modo, fique já aqui enunciado que o escopo deste artigo é apenas parcelar e mais da ordem do esquisso do que de um desenho acabado. Uma vez que determinar com rigor o conceito de país n'Uma Viagem à Índia implica levar em linha de conta o mesmo conceito, com o mesmo rigor, em Os Lusíadas, torna-se evidente que a dimensão de tal trabalho não cabe no espaço de um artigo como este. Grande parte das problemáticas do texto camoniano estão directamente relacionadas com o conceito de país, e, mesmo as que possam não estar, facilmente nele são engajáveis. Ficaremos, portanto, por uma abordagem mais modesta, apenas introdutória, ao texto de Gonçalo M. Tavares, lendo o como um texto fechado em si-mesmo, deixando desde já enunciada a investigação futura 
do estudo comparativo, que decerto ampliará, reconfigurará e corrigirá este trabalho inaugural.

\title{
2. 0 conceito de país em Uma Viagem à Índia
}

\subsection{Mapeamento de negações}

Para uma abordagem da problemática da nacionalidade n'Uma Viagem à Índia, devo, em primeiro lugar, frisar que M. Tavares não predetermina à ideia de país qualquer contexto de ordem pragmática, o que anula os critérios externos (à linguagem) habitualmente utilizados para balizá-la. A anulação de tais critérios é, inclusive, afirmada de modo explícito na obra. Traçarei aqui um breve mapa destas negações com o intuito de pôr em evidência as posições do autor sobre esta temática.

0 primeiro critério externo que Tavares nega à construção do conceito de país é o de territorialidade. Para este autor, as formas de demarcação de fronteiras são artíficios associados a uma taxinomia cujo critério obedece a uma lógica de autoritarismo humano:

\author{
(...) Porque cada mapa humano \\ ilustra apenas um dicionário \\ de guerreiros: múltiplas gerações que venceram \\ decidiram o nome de uma terra. \\ Porém, a terra é um elemento castanho e \\ antigo: antes da guerra e da desordem \\ havia a paz, e aí o ar tinha já pousado \\ o nome verdadeiro de cada montanha \\ sobre cada montanha verdadeira. (UVI, VI, 12: 2-10)
}

Tais fronteiras autoritárias são aquilo que fomenta a negação da compartilha, da cooperação, da amizade, enfim, do relacional entre gentes e entre gentes e o mundo (UVI, I, 52: 1-4), gerando antes processos de incomunicabilidade absoluta, comparativos, competitivos, que, a serem relacionais, são-no de forma a estimular tão-só instintos primários: exclusivamente destruidores, simiescos, cúpidos, predatórios, servis. Além disso, fazem os países funcionarem como organismos metafísicos, ou seja, como grandes 
abstracções que garantem a sua grandeza dominadora à custa do esmagamento do valor singular de pequenas concretudes, tendendo ainda a não admitir concretudes inúteis no que respeita a servir o propósito de fazer funcionar tal organismo:

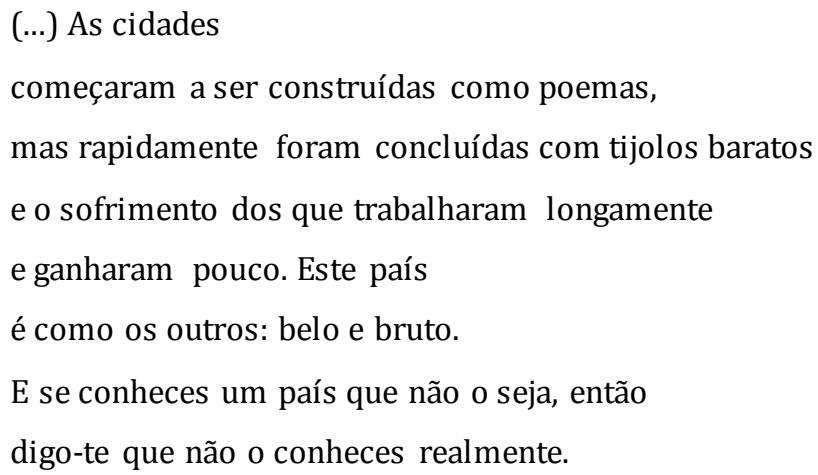

Pelos motivos expostos, a obra denuncia a profunda artificialidade fixadora destas demarcações territoriais de índole política, ora pondo-as em causa através da explanação dos potenciais efeitos devastadores das forças da natureza (UVI, VI, 72: 4-7), ora expondo o vazio não vivenciável da sua imaterialidade abstracta (UVI, II, 110: 7-10), ora ainda questionando que um homem possa ser visto apenas como parte de um todo - afirmando que, pelo contrário, uma grande extensão territorial é parte de um homem (UVI, IV, 31: 1-2; 4-6).

Um segundo critério externo que Tavares nega ao conceito de país, e que está directamente ligado ao precedente, é o da legitimidade. As leis de estado, tanto civis como religiosas (morais), não passam, para ele, de instrumentos de linguagem que (re)forçam o 
autoritarismo humano acima referido (territorializante), quer pela repressão relacional que exercem na sua aplicabilidade (UVI, V, 58: 1-63), quer pelos seus efeitos alienantes mortalmente entorpecedores (UVI, III, 14-5: 2-10; 1-10) -, quer pelo seu cariz apropriador e normalizador da linguagem diferenciada e diferenciante - entenda-se, a linguagem poética (UVI, V, 99: 1-5) -, coarctando, destes três modos, três espécies de liberdade: a de acção, a de pensamento e a de expressão. Pelo que a obediência às mesmas configura, não o respeito por qualquer espécie de justiça justa, mas tão-só um temor da autoridade.

Considero de extremo interesse, para coadjuvar o exposto no intuito de poder darlhe outra amplitude e perspectiva, convocar, neste ponto da análise, dois momentos do raciocínio de Jacques Derrida acerca da fundação do direito.

0 primeiro trata-se de perceber o acto fundador como acto sem fundamento, lo go provido de uma força performativa que "implica sempre uma força interpretativa e um apelo à crença" (Derrida, 2003: 23) e que nunca pode ser "inscrito no tecido homogéneo de uma história, porque o rasga com uma decisão" (Idem: 24). A operação de inaugurar, de fazer a lei, consiste, pois, numa violência sem fundamento que:

(...) em si mesma, não é justa, nem injusta, e de que nenhuma justiça, nenhum direito prévio e anteriormente fundador, nenhuma fundação pré-existente poderia, por definição, garantir, contradizer ou invalidar.

(...) 0 discurso encontra ali o seu limite: nele mesmo, no seu próprio poder performativo. É o que eu proponho chamar aqui (...) o místico. Existe ali um silêncio murado na estrutura violenta do acto fundador. Murado, emparedado, porque este silêncio não é exterior à linguagem. (Ibidem)

Derrida acrescenta que este acto fundador, por condição de performativo, assim como excede a oposição do justo e do injusto (no sentido da justiça como direito, isto é, excede a oposição do legítimo e do ilegítimo, do legal e do ilegal), excede também, consequentemente, a oposição do fundado e do não-fundado, e por este motivo, mesmo quando é extremamente bem-sucedido, como por exemplo quando dá origem a um Estado como garante de um direito que supõe condições e convenções prévias (como por exemplo, as de território), ele não deixa de encontrar nessas condições e convenções prévias o mesmo limite místico. 
E é aqui que surge o segundo momento do seu raciocínio, que consiste em retirar, desta condição de performance do acto fundador do direito, ilações que diferenciam o mesmo direito da justiça e, em simultâneo, com ela estabelecem uma relação intrínseca ao ponto de fundamental:

Na estrutura que assim descrevo, o direito é essencialmente desconstrutível, seja por ser fundado, quer dizer, construído sobre camadas textuais interpretáveis e transformáveis (e é a história do direito, a possível e necessária transformação, por vezes o melhoramento do direito), seja porque o seu último fundamento, por definição, não é fundado. Que o direito seja desconstrutível não é uma infelicidade. Podemos mesmo encontrar nisso a chance política de todo o progresso histórico. Mas o paradoxo que eu gostaria de submeter à discussão é o seguinte: é esta estrutura desconstrutível do direito ou, se preferirem, da justiça como direito que assegura também a possibilidade da desconstrução. A justiça em si mesma, se uma tal coisa existe, fora ou para além do direito, não é desconstrutível. Tal como a própria desconstrução, se qualquer coisa de tal existe. A desconstrução é a justiça. (Idem: 25-6)

Associando as ideias derridianas aos efeitos coarctantes denunciados por M. Tavares, torna-se evidente que a justiça pré-escrita é, para este último, justiça prescrita, que às leis deve-se desobediência por respeito, não de qualquer livre arbítrio, mas de uma liberdade tanto justa, quanto (acrescento eu) ética - problemática, quero dizer.

Outros dois critérios sobredeterminadores - que estabelecem arreigadas relações com os já expostos neste estudo - negados ao conceito de país por M. Tavares dizem respeito à língua e seus usos: o da extensão demográfica do campo da palavra e o da dominação da "língua" (de Estado) em relação ao uso da palavra, dialecto ou idioma:

A linguagem de um país não se amplia

através do território, como é evidente.

(...)

Se o exército conquistar um edifício, e nele,

a partir desse momento, apenas se falar a língua da pátria, não julgue que a língua fica mais rica.

A língua não é proprietário que soma metros quadrados

a arfar de satisfação. A língua aumenta 
quando alguém escreve ou diz algo

portador de uma levíssima corrupção da norma (...)

A língua aumenta com os erros exactos,

não com maiores desenhos nos mapas.

Em certas águas-furtadas, de seis metros quadrados,

enriquece-se mais a língua,

com trabalho fundamental sobre as palavras,

que nos grandes campos de batalha, nas invasões súbitas

e barulhentas. (UVI, IV, 33-4: 1-8; 1-9)

Eis, por conseguinte, na língua, uma possibilidade das singularidades (e dos povos menores e colonizados (UVI, VI, 33: 3-6)) se furtarem ao domínio autoritário territorializante e legitimador. Progredir na língua é, num mesmo movimento, apropriar-se dela despojando-se ${ }^{4}$, isto é, conquistar nela aquilo que nela ainda não existe - uma salvífica linha de fuga "estrangeira" 5 -, corrompendo criativa e subtilmente - com senso de justiça, desconstrutivamente (e não à bruta - destrutivamente, através de uma reificação do livre arbítrio ) - aquilo que a delimita e normaliza. 0 que passa por habitar não o seu interior, cuja atmosfera está carregada de forças centrípetas, nem o seu exterior centrífugo (absoluta incomunicabilidade, puro estrangeirismo predatório, colonizador, impartilhável, inconciliável, que apenas o intermédio tradutor pode apaziguar (UVI, VII, 45-6: 1-10; 1-11)), mas a sua orla indecidível e inencontrável, onde forças antinómicas (erros exactos) causam tensionamentos que dirimem a rigidez das fronteiras e permitem abrir caminhos por onde avançar (UVI, VII, 32: 7-11). Habitá-la como um nómada, mesclando-a com o corpo escrevente (performativo) e o mundo percepcionado imaginativamente, erguer essa casa poética no centro do desmoronamento, e nessa vertigem inventar ainda uma tranquilidade (UVI, V, 16: 1-8) - temporária, ciente da sua humana precariedade - que perpetuamente renova a exigência de movimento como modo de sobrevivência.

Indissociável das considerações de Jacques Derrida acerca da desconstrutibilidade do direito é o factor histórico, factor que, de um certo ponto de vista, M. Tavares nega também como critério sobredeterminador do conceito de país. E esse certo ponto de vista, 
já decerto enunciado neste trabalho, é o que as narrativas autoritárias sustentam, quer pela reiterada exaltação do frenesi cúpido e dominador dos antepassados autóctones - pólo dominador -, quer pela reprodução mimética dos costumes e tradições (tanto práticas, como doutrinárias, como ainda estritamente linguais) - pólo dominável. Narrativas de origem antiga, às quais são retirados o carácter ficcional e poético (inapreensível, secreto), transformando-as desta maneira em supostas Verdades (que acentuam o autoritarismo, credibilizando-o sob uma máscara "realista") concernentes a heróis cujo heroísmo encontra actualização nos todo-poderosos actuais:

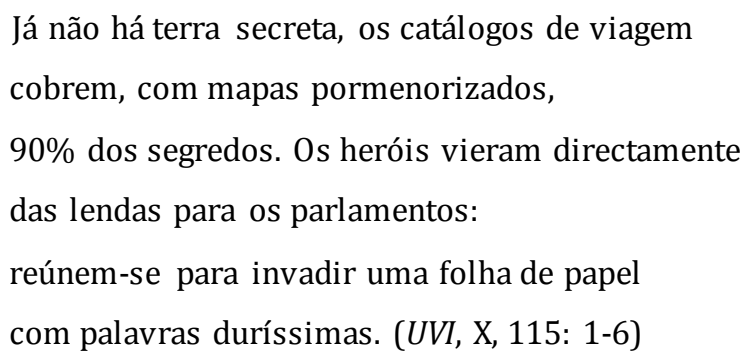

Mapeadas as negações do conceito de país, observa-se que em todas elas a palavra, sempre sob o domínio de uma força autoritária (UVI, VII, 81: 6-9), cumpre papel fulcral, fazendo-se notar também que, empiricamente, elas concorrem para a manutenção e o desenvolvimento de um modo de vida padronizado de índole predatória (talvez não seja inadequado chamar-lhe paranóica) e de elevada potência disseminadora - de inequívoco alcance universal (UVI, X, 50: 5-10).

\subsection{Formação do conceito de país em relação com as noções de tempo e espaço}

Impõe-se agora o questionamento do que é um país para M. Tavares, já que ele não nega tal conceito, mas tão-só aqueles critérios externos que o sobredeterminam. Vou mais longe e afirmo que, na sua óptica, um país é um conceito que sai desta lógica autoimpositiva, entenda-se, que sai da própria possibilidade de sobredeterminação por via de qualquer meta-linguagem, de qualquer fundamento místico. Implica isto um devir intrínseco ao conceito, uma força metamórfica que não lhe permita fixar-se sob nenhuma 
forma estanque. Um conceito, por conseguinte, em permanente restruturação, cuja força não é bruta nem modeladora mas delicada e maleável - que não assenta numa intensidade estúpida nem simplificada, mas inteligente e complexa. Uma força fugitiva, cobarde, que se furta ao círculo fechado da dominação, e nessa cobarde saída para fora desse círculo encontra a sua coragem - em suma, uma força que faz da sua extrema fraqueza a sua extrema potência:

De que é feito um país cobarde?
Bloom responde: é feito de muitos homens
corajosos. (...)
Um país corajoso é feito de habitantes vivos
bem tratados, bem alimentados,
capazes de imaginar o invulgar
na língua que os seus pais usavam. (UVI, IV, 32: 1-10)

Ditas algumas coisas, a meu ver, fundamentais, gostaria agora de dar outra amplitude ao conceito de país em Uma Viagem à Índia, pensando-o em relação com outros conceitos, o primeiro dos quais o de espaço. O sublinhado de que um país é um conceito, e que traz por esse motivo consigo a implicação de apenas existir na língua, permite a óbvia dedução de que só a inteligência humana pode a ele aceder, pelo que o seu espaço serve para a exclusiva existência desta espécie6: "Um país deveria ser um espaço / para o povo existir, mas o povo não existe (...)” (UVI, VII, 31: 1-2).

Espacialmente, o país gonçalino não é, pois, qualquer coisa que exista (porque não existe também o que o pressupõe), mas que deveria existir, uma utopia que se quer ver realizada. É nesse sentido que são aceites mapas por M. Tavares, mas mapas utópicos que saiam de toda a lógica autoritária, não oprimindo a possível existência de um povo, como por exemplo os que demarcam diferenças de paisagem natural (UVI, V, 76: 8-11) (que continuamente devêm, é bom não esquecer), assim como é por ele admitida uma representatividade nacional quando a taxinomia empregue se reporta à materialidade concreta de tais paisagens $(U V I, I X, 62)$ (no seio da qual é possível uma concreta existência 
humana).

Outro aspecto que corrobora a asserção de que um país é um espaço de criação (de existência) exclusivamente humana é o dele se constituir daquilo que permite a subsistência desta espécie, e tal assumir-se, para o autor, como um facto histórico (termo que elucidarei ao analisar o conceito de país em relação com a noção de tempo):

\author{
Eis outro facto histórico: a biografia de um país \\ passa também pela gastronomia profunda: o que é um povo \\ senão o que come? Por mais que falem da língua, \\ da cultura e dos hábitos elevados, um povo, \\ tal como um organismo de cidadão individual, \\ é o somatório dos elementos ingeridos, \\ do oxigénio que o ar disponibiliza \\ e do resto, da água, por exemplo. (UVI, I, 79)
}

Ressalta, tanto desta citação, como da anterior, o facto de um país servir para a existência de um povo, de um ente colectivo. Olhado, porém, aqui em toda a sua materialidade, tal ente colectivo deve habitá-lo não de forma comum (como-um), mas em comum, na forma de um conceito que em cada elemento individual se singulariza pelo efeito da empiria impartilhável de cada um, ainda que os elementos externos que lhe dão origem sejam compartilhados.

Se se reparar com atenção nestes exemplos do que é um país na relação com a noção de espaço, observar-se-á que em todos eles também a noção de tempo está presente. Na verdade convém manter em mente que, para $M$. Tavares, a dimensão que o ser humano realmente habita é a temporal, pelo que o espaço que pode dar um conceito de país não pode ser senão exterior ao estritamente espacial: um espaço temporal (inevitavelmente histórico, no sentido em que já de seguida interpretarei a História) ou um tempo passível de se espacializar numa eventual simultaneidade material:

\footnotetext{
A Índia é um país grande. Não pela

extensão mas porque é antigo. 0 tempo, num
}

N. ${ }^{\circ} 38-6 / 2018$ | 439-457 - ISSN 2183-2242 | http:/dx.doi.org/10.21747/21832242/litcomp38v8 
país inteligente, é a extensão mais significativa.

Milhares de metros quadrados ocupam, em teoria,

uma superfície importante.

Também o número de andares dos edifícios

é facto bem visível das janelas dos aviões.

Porém, é a História de um país

que dá a intensidade da ligação da árvore à terra.

E cada país é uma árvore. (UVI, VII, 17)

Devo aqui ressalvar que a palavra História não tem a conotação da narrativa histórica que sobredetermina o conceito. Ela é inenarrável, pois é feita de todos os gestos e acontecimentos intrínsecos ao fluido contínuo, cumulativo, irreversível e irrepetível da duração, para os quais todo o homem não só desconhece língua e linguagem apropriada (UVI, V, 71) como só selectivamente (e infinitesimalmente, para se ser rigoroso) pode tomar contacto. Dela o homem, por lhe ser exterior (na acepção da incaptabilidade (UVI, X, 50: 14)), só pode ter uma falsa ideia, contaminada de ficcionalidade (de um esquecimento que recorre à imaginação, portanto), mesmo quando lhe quer dar, por construí-la com recurso "exclusivo" à memória, uma conotação de verdade:

Núpcias da História com a imaginação

provocaram mais filhos e cópulas divertidas

do que as núpcias da Verdade com

a boa memória. Uiva como um lobo, eis

a História do mundo; tem apetite, sente-se

isolada; a História é um fluido que

passa ao lado dos homens, fluido espesso

onde nada se pesca e é impossível nadar

ou navegar; mas mente-se tanto a contar a história

de um país como a história de um amor que

terminou mal. (UVI, VIII, 3)

Proporcionando, porém, por existir na contingência (UVI, X, 59: 1-3), o uso dos sentidos (ligados às faculdades cognitivas ou intrínsecos a elas) de cada homem a 
apreensão de diferentes (e em número muito reduzido) acontecimentos e narrações dos mesmos, assim como diferentes formas de expressar o que sobre tal apreensão se pensa (ou pensa que pensa), a ideia da História de um país é, para cada um, diversa (de onde se infere que não tem um prazo situado na diacronia, não se esgota quando certas classes dominantes, dando lugar a outras, cessam de "consumir" esse país, mas antes vive enquanto este conceito no homem vive (UVI, X, 109)), abrindo-o tanto mais para o futuro quanto mais plural e insondável for (UVI, VIII, 71) por via do factor relacional - admitindo, por maior cruzamento imaginativo de diferentes experiências, maior quantidade e maior diferenciação de possibilidades de vida (mais filhos e cópulas divertidas).

Concluo, pois, que um país, para este autor, não é um conceito meramente abstracto, generalizável, mas forma-se com a decisiva influência das singulares percepções e vivências de todo o tipo de circunstâncias externas - inclusive as ditas "estrangeiras" -, às quais se mesclam igualmente singulares raciocínios imaginativos. Cada país é uma árvore que é um homem («(...) claro que fiz / esta viagem à Índia para me tornar numa nova / árvore, capaz de transmitir vantagens ao velho solo.» (UVI, VIII, 74: 4-6)), portanto passível de desenraizar-se do solo antigo (a língua) sem que deixe, paradoxalmente, de se constituir também desse solo antigo (comum) - o desenraizamento é, pois, sempre apenas parcial, fazendo-se um país também da multiplicidade de singularidades que o povoam (entenda-se, de homens capazes de imaginar o invulgar na língua que os seus pais usavam), nunca num centro inamovível cómoda e privilegiadamente privado, mas deslocando-se perpetuamente (como centros) em direcções diversas para e na periferia, lidando com a privação de comodidade e privando com o Outro em transporte comum (também a língua, que além de solo antigo é meio de transporte e objecto transportado):

Se queres sentir o sabor de um país não te dirijas

ao palácio exuberante

construído no centro da cidade. Vai

de transportes públicos e incómodos

em direç̧ão à periferia. (...) 
Melhor se sente o cheiro de um país

nas latrinas de estabelecimentos degradados,

onde seis homens desagradáveis mijam

de modo paralelo e vigilante,

do que nos perfumes utilizados no centro.

(...). 0 centro é bom, a periferia pior;

Mas o centro é sempre onde nós estamos. (UVI, III, 91-2: 2-6; 1-8)

\section{NOTAS}

1 Nota prévia sobre referências bibliográficas: as citações são referenciadas bibliograficamente de acordo com o Livro de Estilo desta publicação, com excepção de Os Lusíadas e de Uma Viagem à Índia. Nestes casos, para maior facilidade da localização dos trechos dos poemas por parte do leitor, a citação faz-se pelo numeral romano, no caso do Canto, e por numerais árabes no caso das estrofes e versos. As estrofes seguem-se ao Canto depois de uma vírgula; os versos à estrofe depois dos dois pontos. Exemplos: (Lus, III, 15: 4-6) (Luís de Camões, Os Lusíadas, Canto terceiro, estrofe 15, versos 4 a 6); (UVI, VII, 23-4: 6-8;1-4) (Gonçalo M. Tavares, Uma Viagem à Índia, Canto sétimo, estrofes 23 e 24, versos 6 a 8 (da estrofe 23) e 1 a 4 (da estrofe 24)).

20 carácter de elevada densidade intertextual do texto de Gonçalo M. Tavares é assinalado e sumariamente explicitado por José Cândido de Oliveira Martins (2014: 36-7):

On constate que l'écriture de Gonçalo M. Tavares - et, nous le montrerons brièvement, Un voyage en Inde ne fait pas exception - s'avère densément intertextuelle. C'est une création qui s'inscrit clairement dans une tradition littéraire, interagissant avec elle de diverses manières. La fécondité sémantique de ce dialogue se manifeste à plusieurs niveaux, allant de l'intertextualité explicite, sous la forme de citations et de références exprimées dans le discours textuel, jusqu'à une intertextualité plus implicite, sous-entendue dans des réminiscences et des allusions plus ou moins diffuses. [Constata-se que a escrita de Gonçalo M. Tavares - e, como teremos oportunidade de explanar, Uma Viagem à Índia não é excepção - afigura-se densamente intertextual. É uma criação que se inscreve claramente numa tradição literária, interagindo com ela de diversas maneiras. A fecundidade semântica desse diálogo manifesta-se em diversos níveis, desde a intertextualidade explícita, sob a

N. ${ }^{\circ} 38-6 / 2018$ | 439-457 - ISSN 2183-2242 | http:/dx.doi.org/10.21747/21832242/litcomp38v8

455 
forma de citações e referências exprimidas no discurso textual, até uma intertextualidade mais implícita, subentendida nas reminiscências e alusões mais ou menos difusas.] (tradução minha)

${ }^{3}$ Nestes versos, o factor repressão é dado de forma irónica.

4 É este o movimento de Jacques Derrida, quando afirma “'Eu não tenho senão uma língua, e ela não é minha”” (2001: 13).

5 Repare-se como é na "mão estrangeira", no fora-de-si, que reside a possibilidade última de sobrevivência (UVI, X, 119: 1-2).

60 que não quer dizer que o conceito de país não admita seres não-humanos que o povoem. Admite-os, mas não como seres, antes como seres-ditos, como representações humanas daquilo que realmente são.

\section{Bibliografia}

Camões, Luís Vaz de (1990), Os Lusíadas, Porto, Porto Editora.

-- (1981), Lírica Completa, Volume III, Lisboa, Imprensa Nacional - Casa da Moeda.

Derrida, Jacques (2003), Força de Lei, Trad. Fernanda Bernardo, Porto, Campo das Letras.

Derrida, Jacques (2001), o monolinguismo do outro ou a Prótese de Origem, Trad. Fernanda Bernardo, Porto, Campo das Letras.

Lourenço, Eduardo (2002), Poesia e Metafísica, Lisboa, Gradiva.

Martins, José Cândido de Oliveira (2014), "Gonçalo M. Tavares, Un Voyage en Inde: une épopée hantée par la mélancolie et la déception contemporaine", LES LANGUES NÉOLATINES 369, 33-46.

M. Tavares, Gonçalo (2010), Uma Viagem à Índia, Lisboa, Editorial Caminho.

N. ${ }^{\circ} 38-6 / 2018$ | 439-457 - ISSN 2183-2242 | http:/dx.doi.org/10.21747/21832242/litcomp38v8 
João Albuquerque é Mestre (2012) em Estudos Portugueses pela Faculdade de Ciências Sociais e Humanas da Universidade Nova de Lisboa. Frequenta presentemente o doutoramento em Literaturas Hispanicas na Universidade da Califórnia Santa Bárbara, tendo como projecto de dissertação um estudo intertextual entre Fernando Pessoa e Adolfo Bioy Casares. Os seus campos de investigação centram-se nas Literaturas Portuguesa e Latino-Americana, Poesia Épica, Teoria da Literatura e Filosofia Contemporânea. Tem publicado vários artigos nestas áreas no Brasil, em Portugal e nos Estados Unidos da América, com destaque para as três publicações (2013, 2014 e 2016) sobre o Livro do Desassossego de Fernando Pessoa, dois dos quais na revista com revisão por pares da Universidade de Brown, Pessoa Plural. 